are associated with odors, while thalamic and neocortical projections may be involved in the conscious perception of the smell.
The distributed nature of the encoding of the odor information in and between different olfactory structures may explain why nu- merous non-olfactory human pathologies are associated with a diffuse reduction in the sense of smell.

\section{Language: structure, processing and disorders}

Peter Hagoort

Max Planck Institute for Psycholinguistics, Wundtlaan 1, 6525 XD Niimegen, The Netherlands. 0262031892 by David Caplan, The MIT Press, 1992. $\$ 45.00$ (xvi +515 pages) ISBN

This book provides a very good introduction to studies of aphasia for neurologists, speech-language pathologists and neuropsychologists. It approaches this topic from a psycholinguistic perspective, presenting research on and theoretical explanations for a manifold of aphasic symptoms within the context of the most recent cognitive models of speaking, listening, reading and writing. Five chapters are dedicated to different aspects of word processing and their disorders. These chapters review current ideas about the way in which spoken words are recognized, how the meanings of words are represented, how written language is processed, etc. Word-processing disorders such as anomia, dyslexia and agraphia are described in terms of psycholinguistic models for unimpaired word processing. The same procedure is followed in the three chapters discussing disorders of sentence and discourse structure, which are more complex levels of linguistic organization. A final chapter discusses some implications for the diagnosis and treatment of language disorders.

The strength of the book is that it is organized on the basis of our knowledge about normal language processing. However, the implication of this psycholinguistic bias is that one will not be able to find detailed information on the relation between observed neurological lesions and resulting language disorders.

My sole complaint about this book is that, in addition to discussing the outcome of relevant modern research on aphasia, it does not critically review the research methods used, despite the fact that the author stresses the importance of 'on-line' methods in aphasia research These methods monitor language comprehension and production processes as they unfold in real time, millisecond by millisecond. One such on-line method that has recently been applied to aphasia research is the ERP (eventrelated potential) method, in which recorded brain potentials are timelocked to the relevant language processing events. Despite its claimed importance for workers in aphasia research, the book does not provide the reader with a clear picture of such 'on-line' methods. In my view, the reader would have profited from an additional chapter that discussed the advantages and disadvantages of the different research methods that are currently used in aphasiology. This, however, is a minor point and does not affect my main conclusion that this book should not be missed by those interested in a scholarly overview of the current state of the art in aphasia research.

\section{Books Received}

Abram Amsel Frustration Theory: An Analysis of Dispositional Learning and Memory Cambridge University Press 1992. (xiii +278 pages) ISBN 0521 247845

G. Avanzini, J. Engel, Jr, R. Fariello and U. Heinemann (eds) Neurotransmitters in Epilepsy Elsevier, 1992. \$177.00/ Dfl. 310.00 (xv + 420 pages) ISBN 0444 887100

E. Başar and T. H. Bullock (eds) Induced Rhythms in the Brain Birkhäuser, 1992. $£ 117.60 /$ Sfr. 278.00 (xix +483 pages) ISBN 0817635378

Arnold Burgen and Eric A. Barnard (eds) Receptor Subunits and Complexes Cambridge University Press, 1992. $£ 60.00$ (xi +468 pages) ISBN 0521366127

J. Engel, Jr, C. Wasterlan, E. A. Cavalheiro U. Heinemann and G. Avanzini (eds) Molecular Neurobiology of Epilepsy Elsevier, 1992. \$177.00/Dfl. 310.00 (xv +412 pages) ISBN 0444897119

A. J. Hunter and M. Clark (eds) Neurodegeneration Academic Press, 1992 $\$ 42.50$ (xvi + 255 pages) ISBN 012 3619408
Robert L. Isaacson and Karl F, Jensen (eds) The Vulnerable Brain and Environmental Risks: Volume 1 Malnutrition and Hazard Assessment Plenum, 1992. \$65.00 (xv +268 pages) ISBN 03064411489

Robert L. Isaacson and Karl F. Jensen (eds) The Vulnerable Brain and Environmental Risks: Volume 2 Toxins in Food Plenum, 1992. $\$ 69.50$ (xxiv + 332 pages) ISBN 0306441659

Zaven S. Khachaturian and John P. Blass (eds) Alzheimer's Disease: New Treatment Strategies Dekker, 1992.\$99.75 (USA and Canada), $\$ 114.50$ (elsewhere) (xiv +235 pages) ISBN 0824786203

Patrick Kitabgi and Charles B. Nemeroff (eds) The Neurology of Neurotensin New York Academy of Sciences, 1992.\$100.00 (xiv + 374 pages) ISBN 0897667174

Stephen M. Kosslyn and Richard A. Andersen (eds) Frontiers in Cognitive Neuroscience MIT Press, 1992. $\$ 70.00$ (xxix + 699 pages) ISBN 0262111632

Dominic Man-Kit Lam and Garth M. Bray (eds) Regeneration and Plasticity in the Mammalian Visual System MIT Press, 1992. $\$ 75.00(x+252$ pages) ISBN 0262 121697
Jacob M. J. Murre Learning and Categorization in Modular Neural Networks Lawrence Erlbaum, 1992. \$24.95 (xi +244 pages) ISBN 0805813381

Risto Näätänen Attention and Brain Function Lawrence Erlbaum, 1992. f49.95 ( $x x+494$ pages) ISBN 08058 09848

John G. Nicholls, A. Robert Martin and Bruce G. Wallace From Neuron to Brain 3rd edn Sinauer, 1992. £20.95 (pbk) f37.95 (hbk) (xx + 807 pages) ISBN $087893580 \quad 0 \quad$ (pbk); $0 \quad 87893$ $586 \times(h b k)$

S. B. Prusiner, J. Collinge, J. Powell and B. Anderton (eds) Prion Diseases of Humans and Animals Ellis Horwood, 1992. $f 80.00$ (xxvi +583 pages) ISBN 0137203276

F. Samson and G. Adelman (eds) The Neurosciences: Paths of Discovery II Birkhäuser, 1992. Sfr.168.00 (xiv +338 pages) ISBN 0817635033

Howerde E. Sauberlich and Lawrence J. Machlin (eds) Beyond Deficiency: New Views on the Fuction and Health Effects of Vitamins New York Academy of Sciences, 1992. $\$ 125.00(x+404$ pages) ISBN 0897667492 